\title{
Um quisto de Baker complicado
}

Hema Hasmuklal,* Carla Gouveia**

\section{RESUMO}

Introdução: As autoras, com a apresentação deste caso clínico, pretendem alertar para uma situação de difícil diagnóstico por mimetização de diferentes patologias.

Descrição do Caso: O caso clínico que se relata ocorreu numa mulher de 67 anos com quisto de Baker (também denominado quisto popliteu) de características atípicas e com uma complicação rara. Trata-se de um quisto de Baker muito volumoso com extensão para a perna, simulando uma trombose venosa profunda, que surgiu dois anos após artroplastia de correcção de gonartrose e que teve, como complicação, uma infecção.

Comentário: As autoras descrevem as dificuldades de diagnóstico que esta apresentação rara suscitou na abordagem da doente, e as implicações na reavaliação da funcionalidade da artroplastia.

Palavras-Chave: Quisto Popliteu; Infecção; Artroplastia; Gonartrose.

\section{INTRODUÇÃO}

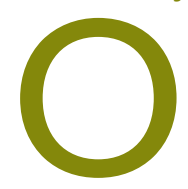

quisto de Baker é um quisto sinovial, originando-se na articulação do joelho. ${ }^{1} \mathrm{Ge}$ ralmente é assintomático. ${ }^{1,2}$ Quistos complicados, com extensão ou ruptura para a perna, podem simular trombose venosa profunda, uma flebite ou celulite, dificultando o diagnóstico ou tratamento ${ }^{2-4} \mathrm{~A}$ sua infecção também é rara. ${ }^{4} \mathrm{O}$ quisto de Baker é um achado raro após uma artroplastia total do joelho, mas quando presente pode indicar má função da artroplastia. $^{5}$

O objectivo da apresentação deste caso clínico é alertar para uma situação de difícil diagnóstico mimetizando diferentes patologias, com necessidade de tratamento atempado, com indicação de reavaliação da funcionalidade da artroplastia, factos para as quais o médico de família tem de estar atento para uma referenciação correcta.

\section{DESCRIÇÃO DO CASO}

C.F.P.S, sexo feminino, 67 anos, caucasiana, casada, habilitada com o $4 .^{\circ}$ ano de escolaridade, reformada de costureira, natural de Granja (Alentejo) e residente em Loures, pertencendo a uma família nuclear, na fase VIII do ciclo familiar de Duvall e na classe IV da classificação de Graffar. O genograma da família encontra-se representado na Figura 1.

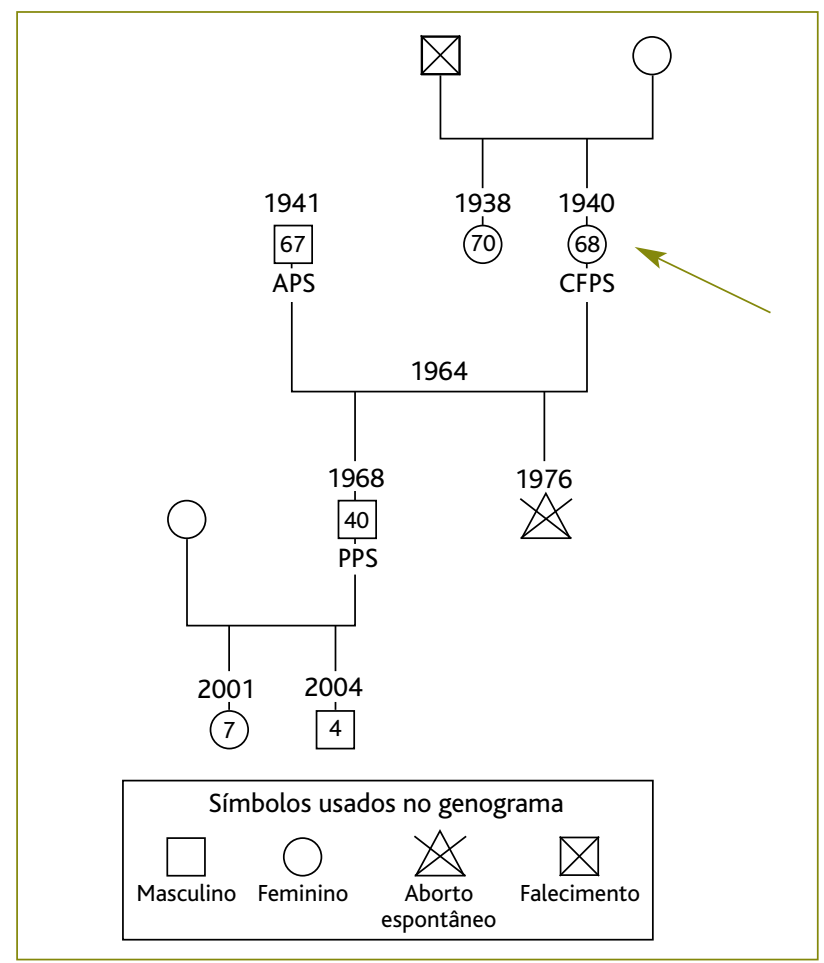

Figura 1. Genograma familiar 
A doente tinha antecedentes de fractura exposta da tíbia direita aos 30 anos, com consequente deformação e encurtamento do membro inferior direito em $19 \mathrm{~mm}$. Aos 54 anos foi-lhe diagnosticada gonartose direita, tendo sido submetida a artroplastia deste joelho aos 65 anos. Sete meses depois foi reoperada por ruptura do tendão quadricípede crural, e no pós-operatório fez gonartrite séptica, tendo-se mantido, desde então, com gonalgia persistente. Há ainda a referir gonartrose à esquerda, e osteopénia trabecular e cortical, encontrando-se a realizar raloxifeno, sulfato de glucosamina e dieta rica em cálcio. Os restantes antecedentes pessoais, hábitos e medicação, história ginecológica e obstétrica não são relevantes para a compreensão da história da doença actual. Sem história de insuficiência venosa dos membros inferiores.

Recorreu ao centro de atendimento de urgências do centro de saúde de Loures no dia 17/05/2007 por apresentar, há cerca de uma semana, tumefacção da região gemelar e maleolar direitas associada a dor exacerbada pela marcha. Por coincidência, foi observada pelo seu médico de família que identificou uma tumefacção da região referida, associada a rubor, calor e dor à palpação local. O sinal de Homans foi negativo, os pulsos eram palpáveis e não existiam alterações tróficas da pele. Foi feito o diagnóstico presumptivo de flebite superficial e a doente foi medicada com diclo-

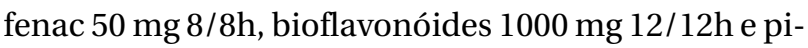
roxicam tópico $8 / 8 \mathrm{~h}$. Por não ter havido melhoria significativa, visitou o seu médico de família novamente no dia $23 / 05 / 2007$, tendo este verificado que a observação se mantinha inalterada. Foi então colocada a hipótese de flebotrombose, embora o sinal de Homans fosse ainda negativo, pelo que a doente foi referenciada ao serviço de urgência do hospital de Santa Maria para realização de ecodoppler venoso.

No serviço de urgência a doente foi encaminhada para a especialidade de cirurgia vascular tendo sido observada e realizado ecodoppler venoso do membro in- ferior direito que não detectou alterações do fluxo sanguíneo. Teve alta com indicação para manter a medicação em curso.

No dia $02 / 06 / 2007$, por manutenção das queixas, a doente recorreu novamente ao serviço de urgência hospitalar, tendo-se observado edema e rubor da região gemelar direita com sinal de Godet positivo e tumefacção supra-patelar. Foram colocadas as hipóteses de diagnóstico de tromboflebite versus celulite. Analiticamente, apresentava hemoglobina 11,6 g/dl, volume globular médio 73,7 fl, PCR de 7,1, provas de função renal hepática dentro dos valores de referência (Quadro I). $\mathrm{O}$ ecodoppler venoso foi novamente negativo e radiografia do joelho direito revelou prótese total do joelho direito sem alterações, com sinais de artrose da rótula (ver Figura 2). A observação pormenorizada excluiu pa-

\begin{tabular}{|c|c|c|c|}
\hline Parâmetro laboratorial & Valor & Parâmetro laboratorial & Valor \\
\hline Eritrócitos & $4,78 \times 10^{12} / L$ & Glicémia & $142 \mathrm{mg} / \mathrm{dL}$ \\
\hline Hemoglobina & $11,6 \mathrm{~g} / \mathrm{dL}$ & Ureia & $45 \mathrm{mg} / \mathrm{dL}$ \\
\hline Volume globular médio & $73,7 \mathrm{fL}$ & Creatinina & $0,8 \mathrm{mg} / \mathrm{dL}$ \\
\hline Hemoglobina globular média & $24,2 \mathrm{pg}$ & Sódio & $138 \mathrm{mEq} / \mathrm{L}$ \\
\hline Leucócitos & $9,86 \times 10^{9} / \mathrm{L}$ & Potássio & $4,2 \mathrm{mEq} / \mathrm{L}$ \\
\hline Neutrófilos & $62,4 \%$ & Alanina tranferase & $20 \mathrm{UI} / \mathrm{L}$ \\
\hline Linfócitos & $28,1 \%$ & Aspartato transferase & $19 \mathrm{UI} / \mathrm{L}$ \\
\hline Plaquetas & $462 \times 10^{3} / \mathrm{L}$ & Lactato desidrogenase & 435 UI/L \\
\hline Proteína $\mathrm{C}$ reactiva & $7,1 \mathrm{mg} / \mathrm{dL}$ & Bilirrubina total & $0,6 \mathrm{mg} / \mathrm{dL}$ \\
\hline Creatina cinase & $174 \mathrm{UI} / \mathrm{L}$ & Gama-glutamiltransferase & $19 \mathrm{UI} / \mathrm{L}$ \\
\hline Urina tipo II & 500 leuc & & \\
\hline
\end{tabular}

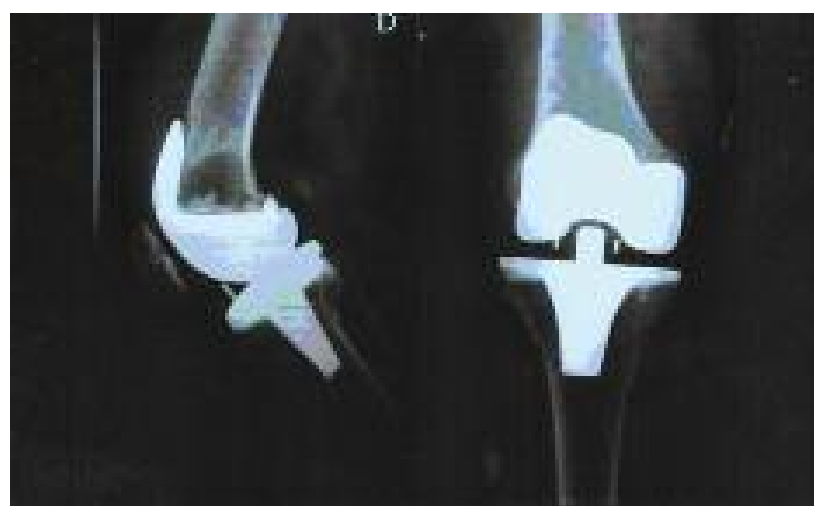

Figura 2. Radiografia simples do joelho direito (2 planos) realizada no serviço de urgência 
tologia dermatológica. Foi internada num serviço de Medicina Interna para estudo.

Em internamento, a doente realizou ecografia das partes moles do joelho direito que revelou derrame articular, espessamento da sinovial e volumosa colecção de parede espessada de $27 \times 6 \times 3,6 \mathrm{~cm}$ na face posterior do joelho, estendendo-se até à região maleolar correspondendo a volumoso quisto entre os planos musculares (Figuras 3 e 4). Uma reavaliação ecográfica (Figuras 5 e 6) revelou ainda a presença de conteúdo não puro. Foi observada em ortopedia que, embora sem tentativa de isolamento de agente, colocou o diagnóstico de quisto de Baker infectado e iniciou terapêutica

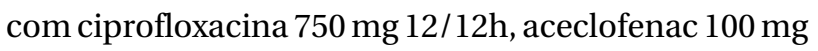
$12 / 12 \mathrm{~h}$ e paracetamol $1000 \mathrm{mg}$ em SOS, se dor irruptiva. Teve alta e efectuou a medicação em ambulatório,
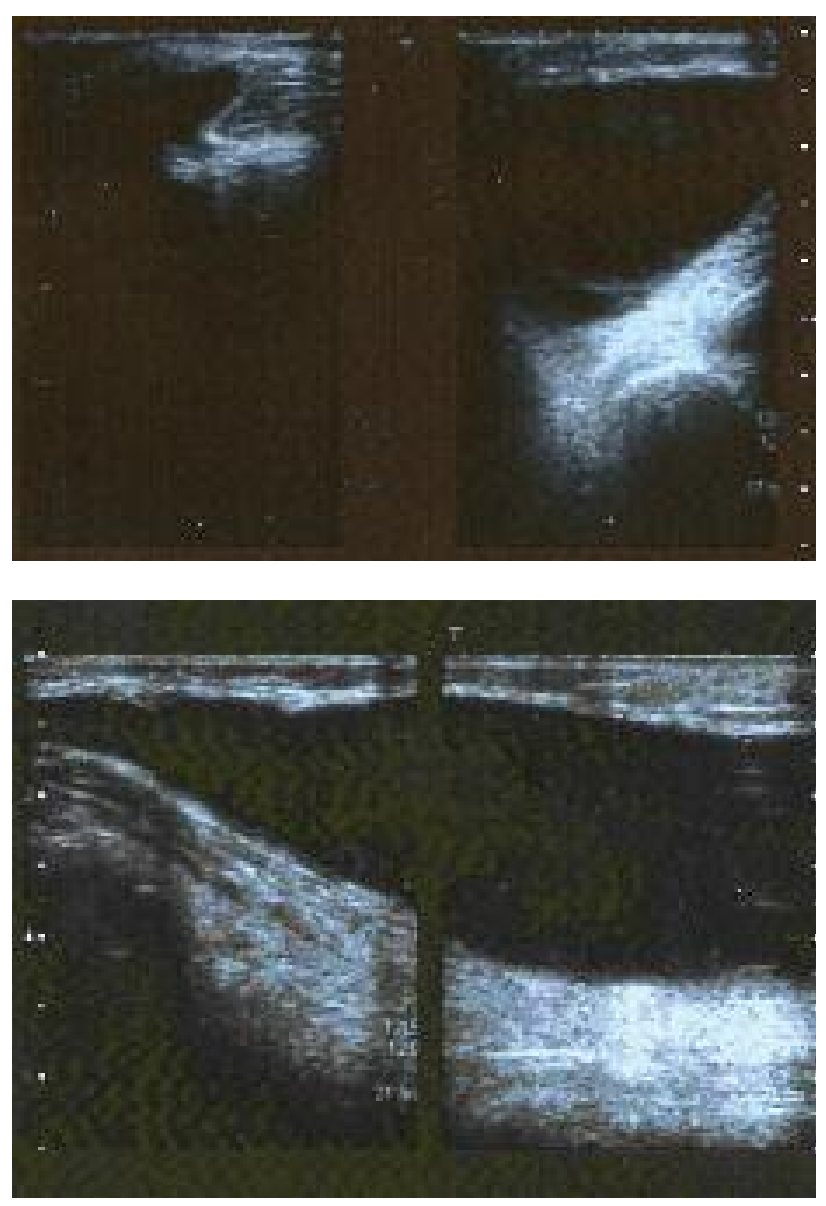

Figura 3 e 4. Ecografia de partes moles do escavado popliteu e perna direita realizada no internamento no hospital de Santa Maria

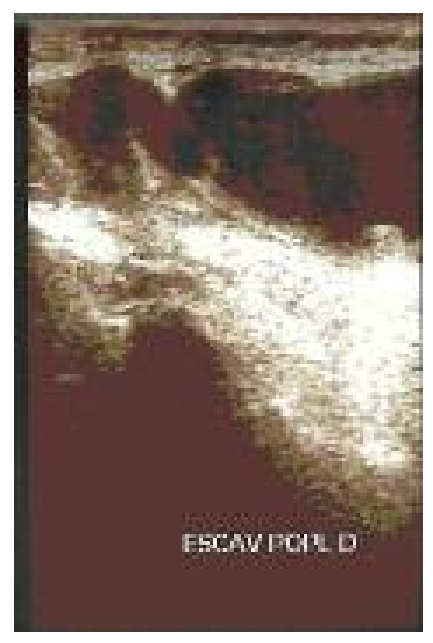

Figura 5 e 6. Ecografia de partes moles do escavado popliteu e perna direita realizada no serviço de urgência do hospital de Curry Cabral

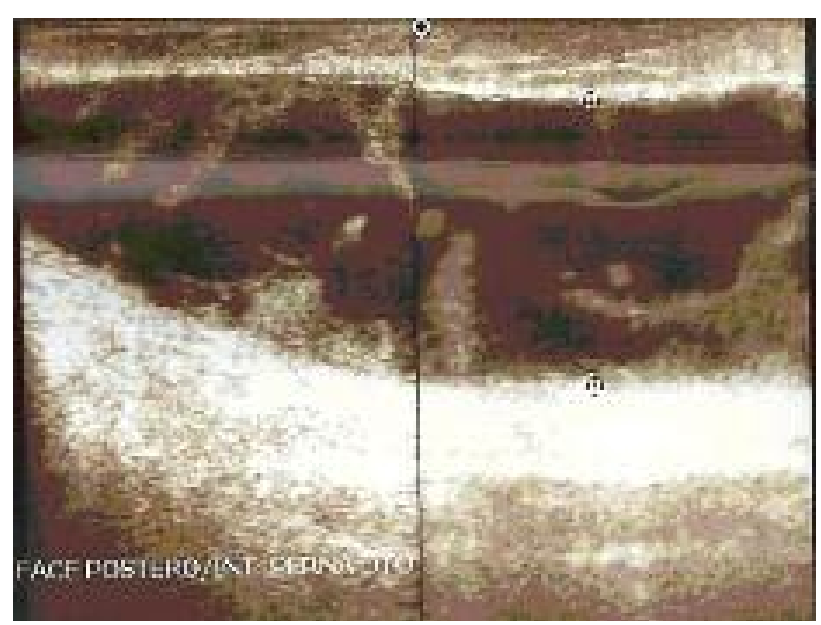

observando-se melhoria clínica significativa.

A doente foi reobservada pelo médico de família quatro meses depois, com melhoria clínica evidente: sem tumefacção visível, sem claudicação da marcha, apresentando apenas ligeiro edema da articulação do joelho. No dia $01 / 10 / 2007$, realizou nova ecografia de partes moles do joelho direito que revelou imagem de pequeno quisto de Baker com diâmetro máximo de $2,5 \mathrm{~cm}$ e contorno inferior irregular, podendo traduzir sequela de anterior ruptura e ainda sinais de moderado derrame articular, mais evidente na bolsa supra-patelar sub-quadricipital (Figura 7).

\section{COMENTÁRIO}

Trata-se de um caso invulgar pelas dimensões do quisto ${ }^{2}$ e pela complicação rara de infecção, ${ }^{4}$ numa doente 


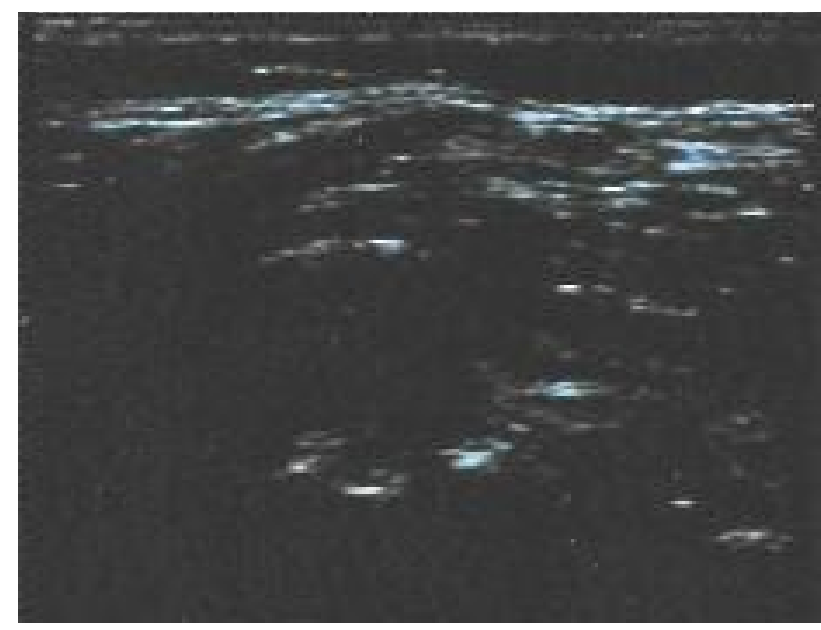

Figura 7. Ecografia de partes moles do escavado popliteu direito realizada em ambulatório após o tratamento

com sintomas inespecíficos. Assim se explicam as dificuldades de diagnóstico.

Quando a abordagem inicial do médico de família não resolve o problema de saúde do doente, como aconteceu neste caso, é necessário recorrer a cuidados de saúde mais diferenciados e com o apoio de meios complementares de diagnóstico.

A apresentação de quisto de Baker que se estende ou sofre rotura para a perna pode simular uma flebite, uma trombose venosa profunda ou uma celulite, e estas podem coexistir em alguns casos. ${ }^{2-4} \mathrm{O}$ diagnóstico é complicado. Nesta paciente foram necessárias várias idas à urgência antes de se poder chegar ao diagnóstico de quisto de Baker, o que apenas foi possível após realização de ecografia das partes moles do joelho, sendo este um exame de eleição. ${ }^{2}$

A dimensão aumentada do quisto de Baker nesta doente poderá ter sido uma consequência da infecção e ruptura do mesmo, uma vez que se verificou diminuição do seu tamanho após tratamento.

A confirmação da infecção do quisto é feita geralmente através de punção do mesmo e análise laboratorial. ${ }^{4}$ Neste caso, foi baseado em critérios imageológicos e clínicos, e pela boa resposta à terapêutica antibiótica, sem tentativa de isolamento de microorganismo.

O quisto de Baker nos adultos é quase sempre secundário a alterações patológicas na articulação do joe- lho que causam um derrame..$^{2,6}$ É um achado raro após uma artroplastia total do joelho. ${ }^{5}$ Quando presente, pode indicar má função da artroplastia relacionada com geração de partículas de revestimento ou devido a lassidão da artroplastia. ${ }^{5,7,8}$ Um quisto popliteu associado a falência da artroplastia do joelho deve ser excisado porque contém partículas de polietileno que constituem um factor de indução para a lassidão da prótese. ${ }^{5}$ Neste caso, além do quisto, a paciente apresenta ligeiro edema do joelho e ecograficamente sinais de moderado derrame articular, pelo que deverá ser avaliada periodicamente e se necessário ponderar a possibilidade de re-intervenção cirúrgica.

\section{REFERÊNCIAS BIBLIOGRÁFICAS}

1. Zhang WW, Lukan JK, Dryjski ML. Nonoperative management of lower extremity claudication caused by a Baker's cyst: case report and review of the literature. Vascular 2005 Jul-Aug; 13 (4):244-7.

2. Handy JR. Popliteal cysts in adults: a review. Semin Arthritis Rheum 2001 Oct; 31 (2): 108-18.

3. Langsfeld M, Matteson B, Johnson W, Wascher D, Goodnough J, Weinstein E. Baker's cysts mimicking the symptoms of deep vein thrombosis: diagnosis with venous duplex scanning.

4. Drees C, Lewis T, Mossad S. Baker's cyst infection: case report and review. Clin Infect Dis 1999 Aug; 29 (2): 276-8.

5. Moretti B, Patella V, Mouhsine E, Pesce V, Spinarelli A, Garofalo R. Multilobulated popliteal cyst after a failed total knee arthroplasty. Knee Surg Sports Traumatol Arthrosc 2007 Feb; 15 (2): 212-6.

6. Fritschy D, Fasel J, Imbert JC, Bianchi S, Verdonk R, Wirth CJ. The popliteal cyst. Knee Surg Sports Traumatol Arthrosc 2006 Jul; 14 (7): 623-8.

7. Ghanem G, Ghanem I, Dagher F. Popliteal cyst in a patient with total knee arthroplasty: a case report and review of the literature. J Med Liban 2001 Nov-Dec; 49 (6): 347-50.

8. Niki Y, Matsumoto H, Otani T, Yoshimine F, Inokuchi W, Morisue H. Gigantic popliteal synovial cyst caused by wear particles after total knee arthroplasty. J Arthroplasty 2003 Dec; 18 (8): 1071-5.

\section{AGRADECIMENTOS}

Ao nosso orientador de internato Dr. Paulo Estrela pelo incentivo e apoio prestado na elaboração do presente artigo, nomeadamente na revisão do texto final.

\section{ENDEREÇO PARA CORRESPONDÊNCIA \\ Carla Gouveia \\ E-mail: carla@clix.pt}

Recebido em 29/10/2008

Aceite para publicação em 12/02/2010 


\section{ABSTRACT}

\section{A COMPLICATED BAKER'S CYST}

Introduction: The authors with the presentation of this case study intended to draw attention to a situation of difficult diagnosis by mimicking different pathologies.

Case Description: The clinical case reports that occurred in a sixty-seven year old women with a Baker's cyst (also known as popliteal cyst) of atypical characteristics and with an unusual complication. It was a very voluminous Baker's cyst appearing with extension for leg, simulating one deep venous thrombosis, two years after a total knee arthroplasty for knee osteoarthritis treatment and had an infection as a complication.

Comment: The authors describe the difficulties in diagnosis that this rare presentation brought up in the patient's assessment, and the implications in the reevaluation of the functionality of the arthroplasty.

Keywords: Popliteal Cyst; Infection; Arthroplasty; Knee Osteoarthritis.

\section{PANTOJA ROJÃO}

António Manuel Pantoja Rojão nasceu em Évora, em 1943. Em 1969, licenciou-se em Medicina na Universidade de Coimbra. Actualmente, exerce Medicina em Lisboa. Foi sócio da Sociedade nacional de Belas Artes e membro da Direcção da SOPEAM (1994-1998).

\section{EXPOSIÇÕES INDIVIDUAIS (1989-2008)}

Casa do Alentejo; Galeria de Arte do Hotel Meridien; Sociedade Nacional de Belas Artes; Pousada da Rainha Santa Isabel, Estremoz; Galeria Municipal da Câmara Municipal de Sesimbra; Palácio D. Manuel, Évora; Museu Regional de Sintra; Museu da Água da EPAL; Museu Alberto de Monsaraz; Sede da Ordem dos Médicos; Auto-Clube Médico Português; Galeria Municipal de Mourão; Fundação Alentejo Terra-Mãe; Edifício Central da Câmara Municipal de Lisboa; Casa Municipal da Cultura de Coimbra.

\section{EXPOSIÇÕES COLECTIVAS (1989-2008)}

Participou em mais de 100 exposições colectivas no país e no estrangeiro, das quais se destacam: VII eVIII Congresso Nacional de Medicina, na Fundação Calouste Gulbenkian; Jogos Médicos Nacionais «O Médico na Arte», Tróia; «Salão do Pequeno Formato», Casino do Estorial; Galeria Marabello, Barcelona; Caixa Geral de Depósitos; «Semana do Castelo», Mourão; Bienais do Alentejo; Criativarte, Reguengos de Monsaraz; Recife - Brasil.

\section{REPRESENTAÇÕES}

Encontra-se representado em várias colecções particulares e de entidades públicas e privadas, nomeadamente: Museus de Évora, Sintra, Portimão, Ovar, Guimarães e Museu da Cidade de Lisboa; Câmara Municipal de Évora e Sesimbra; Hotel Meridien; Enatur; Hospital dos Capuchos; Ordem dos Médicos e Federação Nacional dos Médicos.

Editou várias serigrafias no Centro Português de Serigrafia e na Galeria Aparte.

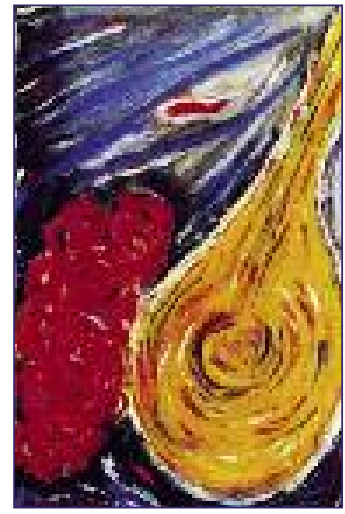

Saudade

Pantoja Rojão

2003, guache sobre papel

\section{DISTINÇÕES}

1994 - Menção Honrosa do Prémio Mário Botas 1998 - Menção Honrosa do Prémio Mário Botas

1999 - Prémio Mário Botas da SOPEAM

\section{BIBLIOGRAFIA}

Das várias referências feitas à sua obra, destacam-se:

- «Artes Plásticas Portugal, O Artista Seu Mercado», 1993, Narciso Martins, Adrian Publishers.

- «Pantoja Rojão Pintura», 1993 - Europeia Seguros - Grupo Wintertur

- «Aspectos das Artes Plásticas em Portugal», 1995, Fernando Infante do Carmo

- «O Mundo Fascinante da Medicina», 1997, do Prof. Armando Moreno

- «Pantoja Rojão», Livro de Artista, 1995 - Edição Pandora

- «Dez Anos de Arte», Retrospectiva da Colecção EPAL, 1998

- «50 Anos de Pintura e Escultura em Portugal», Universitária Editora, 1999

- «Directório de Arte Linhares», 2005/2006

- «Impressões Partilhadas», Centro Português de Serigrafia - 20 Anos a Partilhar a Arte, 2006

- «O Figurativo nas Artes Plásticas em Portugal do Século XXI», 2007, de Afonso Almeida Brandão.

- «Filmografia» - Um filme realizado por Álvaro Queiroz - consta do arquivo da Cinemateca Portuguesa, 2008.

Entre outros escreveram sobre a sua obra, Artur Nobre de Gusmão, Juvenal Esteves, José Luis Porfirio, Margarida Botelho, Edgardo Xavier, Almeida Brandão, Borges Fernandes, João Pinharanda, Rodrigues Vaz, Maria João Fernandes e José de Sousa Machado. 